\title{
Going digital and creating that butterfly
}

Written by: Angel Gurría, Secretary-General of the OECD

Last update: 25 February 2020

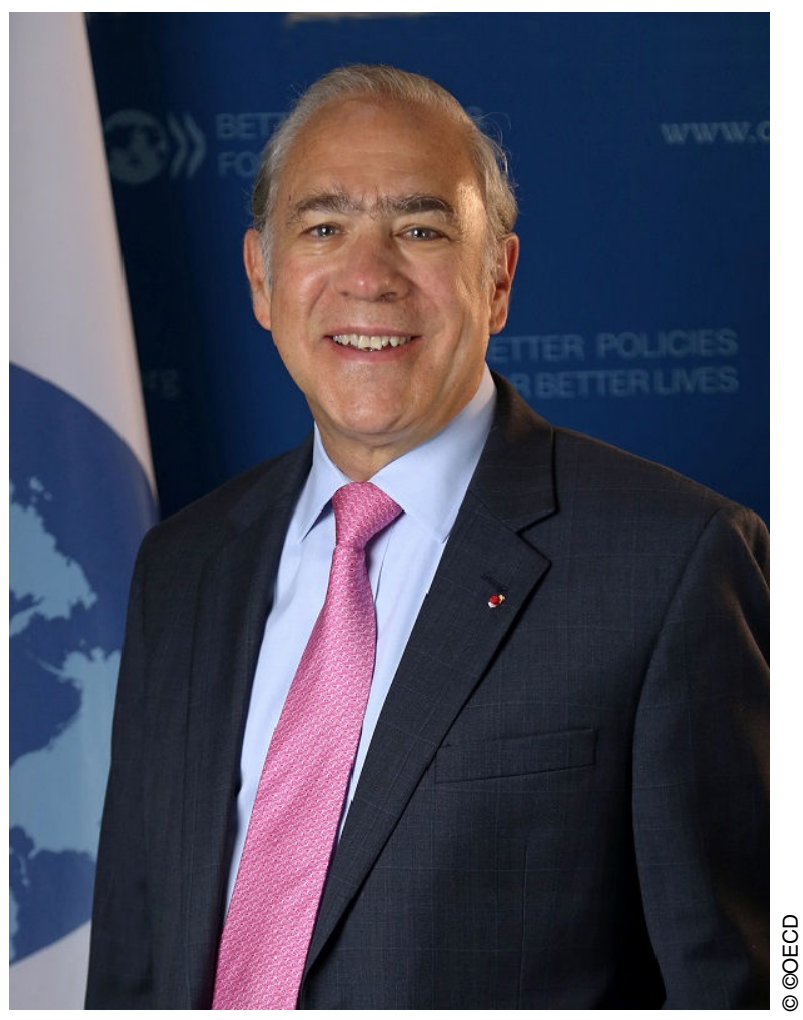

Angel Gurría, Secretary-General of the OECD

The digital transformation is not new, but the pace of change has quickened, with our hyper-connected societies generating huge volumes of data of all kinds.

This flood of data is transforming value generation, decision-making and production, similarly to how new materials or the advent of combustion engines transformed economies and societies in past eras.

This transformation brings countless opportunities to improve well-being, from health care to education to the environment. The smartphone in your pocket can use AI to detect possible health issues, or speech recognition to offer on-the-spot 
translation. Camera-carrying robots can inspect the interior of oil pipelines, looking for fissures and averting environmental damage.

Yet such benefits are accompanied by new pitfalls. Digital transformation is raising concerns about labour market polarisation and skill mismatches, breaches of privacy and security, growing market power for leading firms, and tax evasion and aggressive tax avoidance. It is also raising new concerns about inclusion and equality: more than 4 in 10 rural households don't have access to high-speed broadband, while big data analysis is only performed by $11 \%$ of firms

The benefits and downsides raise challenges for policy makers in weighing costs and benefits associated with different policy options. Ban ride-sharing because it violates rules governing taxis and you may make it harder for poor people to get to work. Overly limit data access because of privacy concerns and you may cut off avenues of research on dementia. At the same time, too light a touch may allow a concentration of power and even undermine democratic institutions.

These issues not only touch virtually every aspect of domestic policy, but also raise many cross-border issues, including digital trade. They have risen to the top of the policy agenda at the UN-including ITU and UNESCO-as well as other international bodies, including the G20, the G7, the EU, APEC and here at the OECD.

In 2016, ministers meeting in Cancun recognised the need for a coherent wholeof-government approach to the digital transformation, and launched the OECD Going Digital project. Work started in 2017 across 10 different OECD directorates, involving more than 14 different policy committees.

From the outset, the aim has been to strive for outcomes that put people at the centre-empowered by digital technologies, not controlled or impoverished by them.

This effort has leveraged the best measurement, analysis and policy thinking, and has allowed us to produce a unique tool for governments-the OECD's Going Digital Integrated Policy Framework.

This is the first time that a holistic policy approach to the digital transformation has been formulated. [...]

We want to bridge digital divides for people and firms. We want to help empower people to succeed in a rapidly changing digital world of work. We want to strengthen trust and enhance access to data to drive innovation. And we want to build the next generation of data and indicators capable of monitoring and shaping the digital transformation. It is an ambitious project, I know, but the OECD can make magic when working with people like you!

A successful digital transformation is about preparing people and governments to turn digital technologies into human development magic. In the words of MIT 
scientist George Westerman: "When the digital transformation is done right, it's like a caterpillar turning into a butterfly, but when done wrong, all you have is a really fast caterpillar." The OECD is ready to help you conceive that butterfly!

For more on Going Digital, visit: https://www.oecd.org/going-digital/

Adapted from the Secretary-General's opening remarks to the OECD Going Digital Summit: The Promises of Digital Transformation, 11 March 2019. For the full original version, see: https://oe.cd/2wJ 